\title{
El Estado peronista frente a las negociaciones colectivas: de las nuevas herramientas institucionales a la legalización de las convenciones colectivas ${ }^{1}$
}

The Peronist State facing collective bargaining: From new institutional tools to the legalization of collective labor agreements

\author{
María Paula Luciani \\ IDAES-UNSAM/CONICET, Argentina, mpluciani@gmail.com
}

doi: http://dx.doi.org/10.15359/abra.34-49.3

\begin{abstract}
Resumen: Aquí analizamos brevemente algunas de las transformaciones observadas en las herramientas con las que contó el Estado argentino para intervenir en conflictos colectivos del trabajo a partir del advenimiento del peronismo. Ello tuvo su corolario en la aprobación de la primera ley de convenciones colectivas en 1953, lo cual significó la institucionalización de un mecanismo que se había practicado durante décadas, con y sin la participación del Estado. La forma legal que adquirió la convención colectiva estuvo marcada por la experiencia política y de gestión acumulada por el peronismo en el poder.
\end{abstract}

Palabras clave: transformación estatal- peronismo - conflictos colectivos del trabajo - agencias laborales - ley de convenciones colectivas

\begin{abstract}
Our aim is to briefly analyze some of the transformations observed in the tools the Argentinean state had in order to intervene in collective labor conflicts from the advent of Peronism. This led to the approval of the first law of collective conventions in 1953, which meant the institutionalization of a mechanism that had been used for decades, with and without State involvement. The legal form acquired by this institution was marked by the political and administrative experience gained by the Peronist state in power.
\end{abstract}

Keywords: state transformation, Peronism, collective labor conflicts, labor agencies, law of collective labor agreements

Fecha de recepción: 08-05-2014 Fechas de reenvíos: 25-08-2014/17-09-2014/30-09-2014/02-10-14 Fecha de aceptación: 15-10-2014 Fecha de publicación: 28-10-2014

El Coronel Juan Domingo Perón emergió como figura preponderante dentro del gobierno militar que tomó el poder en Argentina en 1943. Desde su cargo en el Departamento Nacional de Trabajo (DNT), una agencia del Poder Ejecutivo Nacional (PEN) especializada en asuntos laborales creada en 1907, profundizó sus contactos con dirigentes gremiales y fue el motor de la transformación de dicha institución en Secretaría de Trabajo y Previsión (STyP) en noviembre de 1943. Desde allí, el Estado irrumpió como nunca en las relaciones entre trabajadores y patrones. Mientras que esto llevó a algunos líderes sindicales a profundizar sus vínculos con Perón y su entorno, el mundo empresarial comenzó a dar muestras de inquietud. Pese a que el Coronel agitaba el fantasma de la revolución social y

\footnotetext{
${ }^{1}$ Una versión de este trabajo fue presentada en las VII Jornadas de Sociología de la UNLP (diciembre, 2012)
} 
esperaba que ese temor bastara para convencer a las "fuerzas vivas" de apoyarlo en un futuro proyecto político, para este sector las resoluciones y decretos de la nueva repartición eran las responsables últimas de la activación de las masas. El año 1945, con el fin de la Segunda Guerra Mundial, presentó el escenario en que los partidos políticos buscaron acorralar al gobierno militar y pidieron la reapertura del juego democrático. Las principales corporaciones empresariales se unieron a ellos y el debate entre distintas fracciones de las Fuerzas Armadas no se hizo esperar. En octubre, el gobierno militar de Edelmiro Farrell le daba la espalda a Perón y cuando todo parecía indicar que su carrera estaba terminada, numerosos sindicatos articularon la movilización que confluyó en la jornada histórica del 17 de octubre, fecha central en el imaginario peronista por representar la relación de lealtad de los trabajadores con su referente (Torre, 1990). Estos avatares del juego político hicieron que Perón terminara reclinándose sobre el flanco sindical en su construcción política y que el movimiento obrero adquiriera un protagonismo crucial para investir al peronismo de una tónica que lo distingue de otros movimientos populistas.

Mientras la historiografía se ha dedicado profusamente a analizar distintos aspectos de la relación peronismo-movimiento obrero, y ha puesto la lupa en distintas ramas y gremios, menos ha sido dicho sobre las transformaciones y expansión del Estado en ese período. No obstante, en los últimos años, esto ha comenzado a revertirse y están multiplicándose las investigaciones sobre el funcionamiento y organización del Estado, tanto durante la etapa de los orígenes del peronismo (1943-1946) como durante las presidencias de Perón (19461952/1952-1955). Más allá de la diversidad de recortes y enfoques, estos trabajos están problematizando aquella imagen de Estado monolítico que el propio peronismo construyó y proyectó sobre sus contemporáneos (entre otros Berrotarán, 2003; Rein, 2006; Campione, 2007; Biernat, 2007; Ramacciotti, 2009; Belini, 2009).

Nos enmarcamos en esta línea de interés y proponemos señalar brevemente algunas de las transformaciones observadas en las herramientas con las que contó el Estado para intervenir en conflictos colectivos del trabajo a partir del advenimiento del peronismo, para lo cual focalizaremos en la dimensión del cambio institucional y culminaremos con un sumario tratamiento de la sanción de la primera ley de convenciones colectivas del país en 1953 (Ley 14.250).

Desde la jerarquización de las agencias del trabajo en el organigrama estatal suscitada con la creación de la STyP mencionada más arriba, el PEN fue fortaleciendo su autoridad para terciar en las relaciones capital-trabajo en todo el territorio mediante distintos caminos, sobre los cuales intentamos ofrecer un panorama somero. El DNT, el organismo ejecutivo antecesor, había visto complicada su gestión ante la falta de una fuerte autoridad ejecutiva, y podía mediar solamente "a voluntad de partes" y en Capital Federal y territorios nacionales, con la consecuente fragmentación de los criterios de intervención en los problemas laborales (Lobato, 2007; Soprano, 2000, 2009; Shjolden, 2002).

La sanción de la Ley 14.250 de convenciones colectivas con que se cierra este artículo breve, fue la cristalización legal de una vía negociadora entre el capital y el trabajo que tuvo un desarrollo anterior al peronismo y aún al margen del Estado, pero que fue interpelando a este último de manera lenta y no unilineal durante la primera mitad del siglo $\mathrm{XX}^{2}$. Al mismo

\footnotetext{
${ }^{2}$ El inicio de las prácticas de negociación colectiva entre representantes de la patronal y de los trabajadores para acordar salarios y condiciones de trabajo en Argentina cuenta con antecedentes desde la primera década del siglo XX, en lo cual fueron pioneros los obreros gráficos (Bertolo, 2011). No obstante, más cerca del período que nos interesa, los trabajos de Gaudio y Pilone $(1983,1984)$ destacaron el modo en que las transformaciones sociales y económicas de los 30 condujeron a una mayor extensión de la práctica de la negociación colectiva y del papel del Estado frente a ella. Así, resaltaron que la complejización de la estructura económica, el crecimiento de los sindicatos y de su movilización así como el fortalecimiento de
} 
tiempo, la estabilización de esa práctica en una ley también fue posible en la medida en que las transformaciones jurídicas llevaron a la configuración y consolidación de un área de Derecho del Trabajo, diferenciada del Derecho Civil, que permitió el debate en torno a la singularidad de la convención colectiva como institución. Si bien, dicho proceso tiene sus raíces antes del peronismo y formó parte de un clima de época marcado por el intercambio con otras experiencias internacionales, fue impactado fuertemente por las características que tomó la gestión peronista en el área de Trabajo (Stagnaro, 2012).

La forma que adquirió la legalización de la convención colectiva durante el peronismo tuvo relación directa con estos procesos previos, con el entramado de poder diseñado por el movimiento político, con su relación con el sindicalismo y con la coyuntura particular en que se sancionó. Por tanto, fue una medida producto de una decisión política, que debió valerse de los mecanismos estatales disponibles para concebirse y materializarse. Además, acompasaba al Estado argentino en la formalización y estabilización de una práctica que incluso se había incorporado a las constituciones de otros países latinoamericanos como Cuba, Costa Rica, México y Venezuela ${ }^{3}$.

\section{El área de Trabajo con el advenimiento del peronismo}

\section{En torno a la jerarquización del área}

La expansión de las capacidades estatales venía observándose desde la crisis de los años 30, pero a partir del golpe militar de 1943 se construyó un aparato de intervención permanente. En este contexto, el área de Trabajo fue jerarquizada en el organigrama estatal (Campione, 2007, p. 31).

Estos cambios tuvieron relación con demandas de varios sectores, formuladas desde las primeras décadas del siglo XX, pero acentuadas luego de la crisis de 1930. Desde los ámbitos especializados en Derecho del Trabajo, junto con la pelea por la autonomización de esa especialidad, se remarcaba la necesidad de crear un Ministerio de Trabajo desde 1920 (Hroncich, 1924). Esta opinión también alcanzaba a diputados del socialismo, del radicalismo e incluso de algunas fuerzas conservadoras, que presentaron proyectos de ley a tal efecto desde 1910, sin lograr su tratamiento en el Poder Legislativo ${ }^{4}$. Todavía en 1939, el especialista Antonio Amillano editaba su Legislación Nacional del Trabajo y cerraba el Prefacio solicitando la urgente creación de un Ministerio (Amillano, 1939, p. 15).

Durante los años 30, en los ámbitos empresariales, se reconocía la inadecuación de la estructura ministerial frente a los cambios productivos acaecidos por el proceso de sustitución de importaciones. En 1941, un vocero del Boletín del Trabajo de la República Argentina, ligado a la Asociación Nacional del Comercio, la Industria y la Producción, declaraba que era indispensable la creación de un Ministerio, en vista de los problemas laborales suscitados en pleno progreso del comercio y la industria. Según señalaba, debía establecerse un ámbito para fortificar la legislación en la materia y asegurar su aplicación, dado que el Ministerio del Interior (espacio donde se encontraba inserto el DNT) no podía enfrentar esa tarea. Además, llegaba a pedir la reforma de la Constitución para posibilitar la existencia de nuevos Ministerios (Freigeiro, 1941. p. 19).

la negociación voluntaria, llevaron al Estado, y especialmente a organismos como el DNT, a intervenir pacíficamente y fiscalizar algunos de esos acuerdos en una medida mayor a la luego admitida por el peronismo.

${ }^{3}$ En el debate de la Ley 14.250 salieron a la luz estas cuestiones en las argumentaciones a favor de legalizar las convenciones colectivas, por ejemplo en la exposición del diputado radical Leopoldo Marcó ("Diario de Sesiones de la Cámara de Diputados", Reunión, 1953).

${ }^{4}$ Los proyectos de ley se presentaron en 1916, 1924, 1935 y 1939 (Luciani, 2014). 
La Confederación General del Trabajo (CGT), principal central obrera de Argentina, también reclamaba la jerarquía ministerial del DNT, a la vez que cuestionaba sus limitaciones como órgano mediador en las negociaciones ("Cultivo patronal de la huelga" [1938]; "Males reparables" [1939]; "Una repartición que retrocede" [1939]; "Por el fiel cumplimiento..." [1942]). Los representantes del sindicato más importante del país -la Unión Ferroviaria (UF)- que se reunieron por primera vez con Perón en septiembre de 1943, también pidieron la creación de un Ministerio de Trabajo, en tanto era una aspiración instalada en todas las secciones del gremio (Monzalvo, 1975, p. 66). Este rápido vistazo, parece corroborar que para fines de los años 30, el DNT resultaba una repartición insuficiente para ordenar las relaciones laborales, ya que no estaba investido de la autoridad administrativa suficiente para obligar a las partes a concertar y cumplir acuerdos. Sobre todo, la mayor voluntad negociadora exhibida por los gremios articulados en la CGT reclamaba otro tipo de involucramiento por parte del Estado, que no podía materializarse a través de una institución como el DNT, fácilmente ignorada por la patronal.

Si bien, la creación del Ministerio de Trabajo y Previsión (MTyP) se demoraría hasta 1949 por las limitaciones presentes en la Constitución ${ }^{5}$, en 1943, por el decreto 15.074 , el gobierno militar creó la STyP, a la cual se le otorgó rango ministerial. Su aparición se justificaba explícitamente por la necesidad de contar con un espacio que lidiara, centralizadamente, con los distintos problemas de los hogares obreros, con el control del cumplimiento de la legislación social y la articulación de una política social ("Memoria junio 1946 a diciembre 1951", p. 7-8). Además, se creó sobre la base del DNT, pero absorbió reparticiones como la Dirección de Migraciones, la Comisión de Casas Baratas, la Junta Nacional para combatir la Desocupación, entre otras. También, pasó a centralizar funciones de policía del trabajo que controlaban otras agencias e incorporó a toda repartición dedicada a los asuntos del trabajo en el interior como delegación regional.

La creación de la STyP sería ulteriormente transformada en un hito del peronismo. En una clase dictada en la Escuela Superior Peronista en abril de 1951, Eva Perón manifestaba: "El peronismo nació al crearse la STyP, cuando el primer obrero argentino le dio la mano a Perón" (“Cuando el primer obrero le dio la mano a Perón”,1953). La agencia -y no los hechos de Octubre de 1945-, sería considerada la cuna del movimiento. Dentro del peronismo, se la veía como la base de la organización sindical, la precursora de la unión de los trabajadores y de su dignificación. Estas nociones alimentaron la idea de un antes y después en la gestión estatal frente a los problemas del trabajo, que la historiografía se ha encargado de complejizar, mediante la recuperación del papel activo del movimiento obrero.

Más allá del halo con que el peronismo rodeó a la STyP a posteriori, se apreció un impacto transformador y dinamizador en esta área, desde el momento en que comenzó a actuar. Primero, la STyP -y luego, el MTyP - fue artífice de la nueva fisonomía del Derecho del Trabajo, dada su crucial importancia como fuente de regulación normativa y el poder que pasaron a tener sus dependencias para resolver conflictos laborales (Levaggi, 2006, p. 65). Mario Deveali, uno de los especialistas más importantes en la materia y profesor de la Universidad de La Plata, publicaba un compendio de sus clases de 1951 de la asignatura Derecho del Trabajo y de la Previsión Social, en el que señaló su utilidad tanto para los estudiantes como para quienes habían terminado sus carreras sin tener la oportunidad de actualizarse sobre "esta materia en continua y rapidísima evolución" (Deveali, 1952). Las discusiones legales sobre temas como la diferenciación o unidad entre el Derecho del

\footnotetext{
${ }^{5}$ La Constitución de 1853 fijaba en su texto el número de ministerios en cinco. En 1898 se elevó a ocho. En función de esto, el camino para crear otros ministerios era impulsar una Reforma Constitucional o proponer un reagrupamiento de los ya existentes sin alterar su cantidad. Recién cuando el peronismo concretó la primera opción fue viable la creación del MTyP, contemplada en la Ley Orgánica de Ministerios 13.529 de 1949.
} 
Trabajo, el Derecho Sindical y el Derecho de la Previsión Social; el concepto de asociación profesional y los requisitos para su reconocimiento; los problemas devenidos de la indefinición sobre la naturaleza y extensión de los convenios colectivos, etc. estaban en constante retroalimentación con las novedades que aportaba la gestión gubernamental. EI Estado pasaba a tener una incumbencia definitiva en las relaciones del trabajo y su intervención inclinaba la balanza a favor de quienes venían bregando por la separación del Derecho del Trabajo en relación con el Civil ${ }^{6}$.

Asimismo, se observaron novedades en los nichos de reclutamiento estatal. Los hombres elegidos al frente del área comenzaron a proceder del gremialismo. Aunque Perón y Domingo Mercante -el Teniente Coronel, quien fue su compañero de armas y que devino su mano derecha en la gestión- provenían de los círculos militares y marcaron el rumbo de la STyP entre 1943 y 1946, con la asunción de su mandato constitucional, Perón convocó a José María Freire para encabezar la dependencia. Freire, oriundo del recientemente creado gremio del vidrio, se mantuvo en el cargo hasta 1953, cuando fue relevado por Alejandro Giavarini, ferroviario de los Talleres de Pérez, ligado a la UF y que inició tempranamente su contacto con el gobierno militar a través de un cargo en la delegación regional Rosario de la STyP (Luciani, 2014). De este modo la jerarquización del área no fue acompañada por una política de designación de especialistas a la cabeza de la agencia, sino que por primera vez personas con un pasado obrero llegaban a elevados cargos ejecutivos. Esta innovación, además de ser redituable en términos políticos y simbólicos, aportaba saberes prácticos forjados en el conocimiento de los gremios, que resultaban de mucha utilidad a la gestión.

\section{Nuevas herramientas y reparticiones para los problemas colectivos del trabajo: la Dirección de Trabajo y Acción Social Directa}

La imagen rupturista que el peronismo y algunas de sus interpretaciones formularon sobre el impacto de la STyP en el mundo del trabajo y en el desarrollo de las convenciones colectivas se apoya en una resolución de marzo de 1944 (la n. ${ }^{\circ} 16$ ) en la que se fundó el carácter "obligacional" de las convenciones, lo cual sucedió por vez primera y dotó de nuevos sentidos a la intervención estatal. A partir de entonces, habría una institución envestida de la autoridad para supervisar las negociaciones entre las partes y de hacer cumplir lo acordado. A través de la Resolución 16 se estipulaba que tanto trabajadores como patrones debían plantear detalle de sus reclamaciones ante la STyP, que sería la encargada de investigar su fundamento, período durante el cual se obturaba la aplicación de medidas de fuerza (huelgas, cierres y despidos) bajo consideración de falta grave que podía detener la instancia conciliatoria para la solución del diferendo. También se dispuso que los arreglos debían ser redactados ante la Dirección de Acción Social en colaboración con la de Trabajo $^{7}$. Se estaban configurando normas de procedimiento en el terreno, aun cuando todavía no existía una ley.

Para darle mayor respaldo a esta medida, en agosto del 1944 el PEN dictó un decreto (el 21.877/44) en el que se fijaban penalidades para personas y entidades que dificultaban el accionar de la STyP. Los castigos iban desde la imposición de multas hasta el arresto y el retiro de personerías jurídicas o de patentes, para cuya aplicación -en algunos casos- se autorizaba a la STyP a recurrir a la fuerza pública. Para el caso puntual de los convenios colectivos, además de penas pecuniarias y prisión para los patrones, las organizaciones gremiales eran instadas a cumplir con lo acordado bajo amenaza de declarar ilegal su actitud y de no ser atendidas en el futuro por las autoridades de la STyP (Derecho del Trabajo, 1944).

\footnotetext{
${ }^{6}$ El proceso de autonomización del Derecho del Trabajo combinó la acción de abogados y legisladores a partir del momento de la identificación de la 'cuestión social', presentando un salto a partir del peronismo (Palacio, 2013, Stagnaro, 2012)

Esas direcciones se unificarían más tarde en una única Dirección General: la de Trabajo y Acción Social Directa.
} 
Las cifras que la dependencia mostraba para dar pruebas de su éxito en la promoción de convenios colectivos revelaban que mientras que entre 1936 y 1940, se habían firmado 46, solo en 1944 alcanzaban los 142. Fue en relación con esto que los estudios de Gaudio y Pilone $(1983,1984)$ rechazaron que la STyP se adjudicara el papel de gestora de una nueva "normalidad" en las relaciones obrero-patronales. En lugar de considerar al Estado como factor explicativo y causal del desarrollo de las convenciones colectivas, sostuvieron que hubo un previo subregistro en los datos oficiales debido a que pese al fortalecimiento de la práctica de negociación colectiva, muchas de estas instancias se desenvolvían de manera voluntaria y privada.

Aquí no se trata de desconocer el impacto de la movilización obrera en los años 30 y su protagonismo para mejorar sus condiciones de vida, sino de apreciar que el nuevo ordenamiento que impuso el Estado desde 1943 condicionó tajantemente la relación capitaltrabajo. La prohibición del recurso a medidas de fuerza sin conciliación frente al Estado, pasaba a darle una centralidad inédita en las relaciones de poder y protesta entre las clases sociales y lo facultaba para aceitar y normalizar la práctica de las negociaciones y el cumplimiento de acuerdos colectivos y de la legislación obrera en expansión. La premisa era evitar el recurso a la acción directa de parte del movimiento obrero y reducir estrategias evasivas y dilatorias de la patronal. A partir de ese momento, buena parte de las reformas laborales avanzaron, de tal manera que se instó a las partes a negociar acuerdos paulatinos y parciales por rama de actividad, en lugar de condensarse en leyes o incluso en un Código de Trabajo de alcance general. Esto último, además, las resguardaba de la posibilidad de una resistencia empresarial en bloque (Doyon, 2006, p. 112-117).

De este modo, se prefirió avanzar de manera pragmática y se otorgaron mejoras negociadas colectivamente acorde con las relaciones de fuerza prevalecientes en cada sector, sin saldar el viejo debate de si la legislación laboral debía ser ordenada y sistematizada en un cuerpo dotado de unidad de principios y fines, plan rechazado por quienes consideraban que el mundo del trabajo presentaba problemas tan novedosos y cambiantes a cada paso, que pretender sujetar esa variabilidad en un Código significaba someterlo riesgosamente a la inmovilidad (Levaggi, 2006, p. 76-78).

El decreto 23.852 de octubre del año 1945 completaba el elenco de herramientas de la STyP para tratar con las asociaciones profesionales, lo cual invistió de enormes poderes al área. Dicho decreto diferenciaba entre las asociaciones profesionales no inscriptas, las asociaciones profesionales inscriptas, pero sin personería gremial, las asociaciones profesionales con personería jurídica y las asociaciones profesionales con personería gremial. En estas últimas se concentraba, según el abogado y exfuncionario del DNT Unsaín (1945), todo el poder sindical, ya que su reconocimiento les imponía derechos y obligaciones, entre ellas las ventajas de negociar y celebrar convenios colectivos y representar ante instituciones estatales a sus asociados de manera individual o colectiva. Este sistema formaba parte de una estrategia política para insistir en las ventajas de la sindicalización de los trabajadores y utilizar el otorgamiento o revocamiento de personerías gremiales de modo disciplinador.

Durante las presidencias de Perón, el corazón de la febril actividad de regulación de las relaciones del trabajo y de control del acatamiento a las nuevas normativas fue la Dirección General de Trabajo y Acción Social Directa. Durante el gobierno militar, mientras Perón era Secretario, la dirección había sido conducida por Domingo Mercante, pero en 1946 y hasta 1952, pasó a manos de su familiar Hugo Mercante. Él fue el enlace en los primeros contactos de la UF con Perón, desde su puesto de ferroviario en el puerto de la Capital. Pronto, se incorporó al personal de la STyP; en donde tuvo un importante rol en las jornadas 
de octubre de 1945, cuando ayudó a contactar a los dirigentes sindicales durante la detención de Perón y llegó a ser hombre de confianza de Eva Duarte de Perón, esposa del Presidente, quien desde comienzos de 1946 se instaló en las oficinas de la repartición (Monzalvo, 1975, p. 7; Luna, 1975, p. 258; Zanatta, 2011, p. 80). De nuevo se observa a un trabajador a la cabeza de una de las direcciones más importantes del organigrama de Trabajo, en la línea de lo expuesto más arriba sobre Freire y Giavarini.

Dentro de esta Dirección, las Divisiones de Asuntos Gremiales y Asociaciones Profesionales lidiaban, respectivamente, con la cotidianeidad de las conciliaciones y arbitrajes y el control de las personerías. Además, la Inspección de Delegaciones Regionales daba mayor homogeneidad al tratamiento de estos asuntos en todo el territorio ("Plan de Gobierno 19471951", p. 11-12). Estos funcionarios cumplían un rol clave, puesto que no solo iban en persona a asesorar en la mediación de conflictos, sino que daban directivas técnicoadministrativas para coordinar el trabajo a nivel provincial con el de las autoridades centrales (“Memoria de la STyP", 1947, p. 97-99).

Durante el primer año de gobierno de Perón se aumentó la dotación de personal de la Dirección, dada la multiplicidad de asuntos que requerían de su presencia. Solo en el primer año de gestión se firmaron 127 convenios colectivos, que beneficiaron a casi medio millón de trabajadores ("Memoria del MTyP", 1951, cuadros III y IV). Estos funcionarios forjaban su especialización en el ejercicio de las tareas diarias, así como en una actualización permanente sobre las cambiantes disposiciones legales. Hacia 1951, la Dirección contaba con diecinueve secretarías de conciliación con orden de actuar preventivamente, intervenir con urgencia ante cualquier conflicto y presidir las comisiones paritarias ("Memoria del MTyP", 1951, p. 14-15).

Las funciones de esta Dirección se desplegaron con los beneficios de la experiencia adquirida en el terreno por su personal. La actividad comprendía el manejo diario de la relación con los sindicatos. Esta tarea colocaba a sus funcionarios en el cruce del fuego en todas las negociaciones y los transformaba en blanco de elogios y críticas por parte de los sindicatos y en un buffer de tensión para las disputas al interior del oficialismo. Si en enero de 1948 un gremio tan particular en su relación con el gobierno como la Federación Gremial del Personal de Industria de la Carne ${ }^{8}$ emitía un comunicado de prensa con la expresa finalidad de estimular, apoyar y defender a los funcionarios de la STyP, especialmente a los que encabezaba Hugo Mercante (1948) ("Nuestra Federación apoya...", 1948, p. 5), un año más tarde el mismo gremio mostraba su descontento ante el poder discrecional que tenían los funcionarios: "Un funcionario mal inspirado puede causar un daño enorme, no solo a los trabajadores, sino al propio gobierno de la Revolución con solo ir declarando 'ilegales' las huelgas e informando capciosamente sobre las causas y la razón de las mismas, a fin de hacer imposible toda apelación, con lo que lograría crear una situación de malestar y enfrentar a las masas laboriosas a las autoridades..." "La 'legalidad' de las huelgas", 1949, p. 5).

Ante una intervención de la STyP que suscitaba disconformidad entre los obreros y que pretendía controlar el recurso a la huelga, la responsabilidad podía arrojarse sobre los hombros de los "malos funcionarios". Si los sindicatos sin personería gremial rechazaban las nuevas instituciones porque estas intentaban controlar el uso de la huelga como principal arma de lucha obrera, las organizaciones "encuadradas" podían encontrar intersticios para continuar utilizándola, en donde desautorizaban a la burocracia y evitaban una crítica directa y abierta al oficialismo. El importante número de huelgas desatadas como respuesta a los

\footnotetext{
${ }^{8}$ Sobre la organización de los trabajadores de la carne ver Lobato (2001).
} 
puntos muertos de las negociaciones colectivas durante 1946-1948, seguramente fue un entrenamiento clave para los funcionarios de Trabajo y Acción Social Directa (Doyon, 2006, capítulo 8). De su margen para limar asperezas entre los reclamos obreros y las concesiones de la patronal dependían los alcances de las conquistas que finalmente se obtenían por medio del sistema de convenios colectivos, así como el freno a la transmutación de las tensiones económicas en tensiones políticas al interior del movimiento. Estos intersticios permitían que los sindicatos reconocidos conservaran un importante peso en la lucha por mejorar sus condiciones salariales y laborales, incluso pese al progresivo incremento del disciplinamiento sindical, cuyo momento culminante fue la reforma de los estatutos de la CGT en 1950, que, entre otras cosas, la autorizó para intervenir los sindicatos afiliados (Doyon, 2006, p. 315-321).

\section{Hacia la ley 14.250: institucionalización de la negociación colectiva}

Al momento de planificar el período 1947-1951, la STyP reconocía la necesidad de sentar posición en torno a los organismos en los que recaerían las funciones de conciliación y de arbitraje. Sus autoridades planteaban que los antecedentes nacionales, provinciales e internacionales mostraban tres posibilidades: adjudicar la función a organismos del Poder Judicial, al poder administrador o conformar un sistema mixto. Si bien la segunda opción estaba en funcionamiento y fue la que prevaleció, se ofrecía una interesante argumentación para sostenerla: "Los conflictos referidos no se promueven para obtener la actuación de un derecho consagrado por normas jurídicas vigentes sino con miras a conseguir la implantación de nuevas normas que permiten mejorar las condiciones de trabajo. Ese hecho trae como consecuencia que sea aconsejable acordar esa actividad a organismos que no integren el Poder Judicial, toda vez que la función propia de este es la de resolver conflictos, no la de crear derechos" ("Plan de Gobierno, 1947-1951", p. 86).

Se estaba defendiendo la capacidad del PEN frente al Poder Judicial para arbitrar un nuevo orden de cosas en los asuntos del trabajo, que derivaba eventualmente en la creación de derechos $^{9}$. Cabe destacar que aunque a menudo tanto las posturas estatales frente a la huelga, como el régimen de convenciones colectivas y las normas sobre asociaciones profesionales del peronismo, son considerados desde el punto de vista de su utilización política, en lo formal debieron diseñarse echando mano a reglas, procedimientos y justificaciones alimentados por lógicas legales y estatales que no siempre resultaban fácilmente moldeables (Oszlak, 1980, p. 9-10).

Pronto se redactó un protocolo que detallaba los pasos de la conciliación ante la necesidad de negociar colectivamente un diferendo o un pedido de mejoras: el papel de las asociaciones profesionales o de los actores tomados como representativos; el rol del funcionario conciliador; los caminos por seguir en caso de acuerdo o disenso; las prohibiciones expresas de interrumpir el trabajo durante el proceso conciliatorio; los plazos para resolver, que no podían extenderse más allá de los 30 días y las condiciones bajo las cuales debía recurrirse al arbitraje ("Plan de Gobierno, 1947-1951", p. 90-93). Los procedimientos ejecutivos para articular los intereses del mundo del trabajo iban aceitándose, pero la ley de convenciones colectivas se demoraría y dejaría entreabierta la posibilidad de cuestionarlas.

\footnotetext{
${ }^{9}$ Los roces entre estos poderes de gobierno datan del nacimiento mismo de la STyP, cuando el Poder Judicial cuestionó la constitucionalidad de su régimen orgánico en tanto la absorción de las oficinas del trabajo a nivel provincial y municipal vulneraba el principio de autonomía provincial vigente en la Constitución Argentina. Probablemente por esto, el PEN insistiera en mantener el control sobre las funciones de conciliación y arbitraje en conflictos colectivos (Luciani, 2014, pp. 95-104).
} 
En 1953 el PEN se abocó a consolidar la legalidad de las convenciones con el envío de un proyecto al Congreso, nutrido por los ensayos y errores de una década. Probablemente, el impulso viniera de la inclusión de los Derechos del Trabajador en la Constitución de 1949. También en el capítulo II del Segundo Plan Quinquenal se establecía la necesidad de disponer de una ley que fijara la obligatoriedad de la conciliación, los derechos y obligaciones de las partes y las facultades del MTyP como autoridad de aplicación (“Segundo Plan Quinquenal", 1953, p. 43-44).

El proyecto fue estudiado por la Comisión de Legislación del Trabajo y se aprobó ágilmente en septiembre de 1953. El radicalismo acompañó la votación en general, pero intentó abrir el debate en la Cámara Baja mediante la presentación de objeciones al articulado. Sin embargo, la amplia mayoría peronista en Diputados inclinó la balanza de manera decisiva ${ }^{10}$. Con media sanción, en Senadores la discusión fue más breve.

El texto del proyecto casi no sufrió modificaciones. En su presentación, se fundaba la necesidad de darle tratamiento en el gran desarrollo que habían tenido las asociaciones profesionales en los últimos años y en la urgencia por asegurar la aplicación y eficacia de las convenciones colectivas que, por no tener un marco propio, quedaban supeditadas a "los principios generales del derecho señalados por el Código Civil para toda suerte de contratos privados" ("Diario de Sesiones", 1953, p. 1754), cuando en realidad eran instituciones de otra naturaleza, a tal punto que para designarlas estaba extendida la fórmula de tener "cuerpo de contrato y alma de ley". Esto se relacionaba con que eran, en parte, un acuerdo entre las asociaciones patronales (o un grupo "suficientemente representativo") y el sindicato con personería gremial, pero cuyos puntos, por autoridad ejecutiva, eran extensibles a todos los trabajadores y empleadores de la rama, aun sin haber intervenido en su concertación. Esto hacía que el convenio colectivo superara los límites del contrato del Derecho Civil y se pareciera a una ley.

Los legisladores peronistas defendieron la institución como artífice de importantes conquistas sociales, que no solo atañían a cuestiones salariales, sino a condiciones de trabajo y beneficios previsionales, asistenciales, escalafonarios, etc. En este sentido, a pesar de la derrota del Laborismo y la cooptación de la CGT dentro del movimiento peronista, considerar las convenciones colectivas desde el punto de vista de los trabajadores implica reconocer allí el despliegue de una capacidad de presión económica que implicó avances para la posición obrera tanto en el ámbito de trabajo como en la sociedad, más allá de que se acatara el liderazgo político de Perón ${ }^{11}$.

Los convenios colectivos fueron “...un cuerpo legal separado, paralelo y amplificador del espíritu y los términos de la legislación social general aprobada por el gobierno..." (Doyon, 2006 , p. 286), producto de la movilización de los obreros. Lo que antes de 1943 se había obtenido de manera autónoma, aislada, y a pesar de las escasas herramientas estatales de intervención laboral, se alcanzaba yendo un paso más allá de la propia expansión de las capacidades estatales y presionando a los funcionarios conciliadores y a las patronales. El rearmado de los aparatos del Estado había incorporado en su seno las tensiones sociales existentes. Para reajustarlas es que se buscaba la sanción de una ley específica.

\footnotetext{
${ }^{10}$ La Cámara Baja contaba con 135 diputados peronistas y 14 radicales. Para ver la conformación de la Cámara de Diputados a partir de las elecciones legislativas de 1951, ver Ajmechet (s/a).

${ }^{11}$ El Partido Laborista fue organizado por los sindicatos que participaron en las jornadas de Octubre de 1945 para impulsar la candidatura de Perón en las elecciones, ya que este no contaba con un partido político propio. Una vez llegado a la Presidencia, Perón procedió a la unificación de todas las fuerzas que lo habían acompañado en la campaña, en el Partido Único de la Revolución Nacional, más tarde, Partido Peronista. La CGT también fue progresivamente controlada, sobre todo cuando logró apartarse de su conducción al dirigente telefónico Luis Gay, en 1947, para impulsar en su dirección a figuras gremiales de menor trayectoria (Del Campo, 2005; Doyon, 2006, Torre, 1990).
} 
En el recinto, el bloque peronista conceptuó extendidamente la negociación colectiva como el mejor instrumento para manejar las relaciones laborales, porque conservaba flexibilidad para adecuarse a las características de cada actividad. Varios diputados provenientes del gremialismo, como Juan Carlos García o José Presta argumentaron que la práctica de la negociación colectiva era virtualmente inexistente antes del peronismo en virtud de la tenue incidencia del DNT en su concreción y vigilancia de su cumplimiento ("Diario de Sesiones", 1953, pp. 1755 y 1787) ${ }^{12}$. La consagración legal de las convenciones era vista como una contribución clave del proyecto político en la institucionalización de las relaciones capitaltrabajo.

Por un lado, la extensión de su obligatoriedad a todos los empleadores trabaría definitivamente la posibilidad de contratar mano de obra bajo condiciones diferentes mediante la estrategia de aducir la no pertenencia a ninguna organización profesional o el no reconocimiento de la representatividad del grupo elegido por el MTyP para firmar el convenio ${ }^{13}$. Por otro lado, los únicos capacitados para celebrar convenciones serían los sindicatos con personería gremial, aunque la obligatoriedad de la convención homologada regiría aún para los trabajadores no afiliados, lo cual impediría que estos pudieran competir haciendo arreglos distintos con las empresas ${ }^{14}$. Como contrapartida, los sindicatos oficiales podían conseguir ventajas y beneficios exclusivos para sus afiliados y reservarse los aportes de los trabajadores de toda la actividad, aspectos cuestionados por la oposición radical bajo el argumento de ser violatorios de la libertad sindical.

Si bien la ley fijaba lo que venía sucediendo en la práctica, su sanción en la coyuntura de 1953 responde a dos cuestiones. Una legal, que tenía que ver con que la falta de una ley en la materia, habilitaba fallos contradictorios de parte de los tribunales a la hora de juzgar sobre la aplicabilidad de las convenciones, sobre todo en casos de terceros no intervinientes en el acuerdo ${ }^{15}$. A pesar de la maduración del mecanismo, ante la resistencia de alguna de las partes, seguía abierta la vía judicial para evitar el acatamiento. Estos intersticios minaban la estabilidad en las relaciones laborales buscada por el Estado peronista, así como iban en detrimento del mayor poder que pretendía asignarse al PEN frente al Judicial.

La otra cuestión tiene relación con los reajustes institucionales operados por el peronismo tras la Reforma Constitucional y con el "giro" impuesto por la crisis económica desde 1949, que derivó en el Plan de Estabilización Económica de 1952. Entre sus medidas se encontraba la suspensión de las negociaciones colectivas por dos años. Durante 1953, cuando comenzaba a superarse la crisis, algunos delegados de fábrica estaban obteniendo aumentos de salarios a espaldas de lo estipulado oficialmente (Doyon, 2006, p. 378-381). La Ley 14.250 consagraba el poder del MTyP como instancia única para la homologación de convenios y para su contralor; le daba autoridad para decidir sobre la representatividad de la parte patronal, ante la menor organización colectiva de los empresarios en comparación con los trabajadores y le permitía extender la convención colectiva a otras zonas y prolongar su vigencia si las partes no renegociaban. El Art. 6 reservaba una facultad discrecional al Ejecutivo, al establecer que las convenciones debían ajustarse a las normas legales que

12 En contraposición, la estrategia argumentativa de los diputados radicales fue historizar la institución, extendiéndose sobre sus orígenes y antecedentes, como fue el caso del diputado radical por Entre Ríos, Leopoldo Marcó (Diario de Sesiones", 1953 , p. 1759).

13 Ante la falta de una ley de asociaciones profesionales de empleadores, por el art. 9 del proyecto del Ejecutivo, el MTyP podía integrar la representación patronal con empleadores de la rama o considerar representativo al grupo interviniente. La concesión de esta facultad al MTyP constituía una vía para presionar al capital para que se organizara.

14 Según el texto final de la ley 14.250, por el art. 8 la convención homologada ante el MTyP era obligatoria aún para los trabajadores no afiliados y por el art. 9, regía lo mismo para los empleadores.

15 Los diputados radicales sustentaron su posición de votar en general la ley por este problema. 
regían las instituciones del Derecho del Trabajo, excepto que las cláusulas beneficiaran más a los trabajadores, y "siempre que no afectaran disposiciones dictadas en protección del interés general".

El Estado podía frenar, así, las demandas obreras que resultaran temerarias para la comunidad empresaria o para los lineamientos económicos gubernamentales, al adquirir mayor control sobre las dirigencias sindicales. La ley también otorgaba reconocimiento jurídico a las comisiones paritarias, que debían estar presididas por un funcionario de Trabajo y actuar en la interpretación general de los alcances de la convención colectiva así como conciliar en controversias individuales y darle autoridad de cosa juzgada a los acuerdos alcanzados en su seno. Las comisiones paritarias podían contener y retardar la aparición de conflictos abiertos, incluso dilatar el recurso a la Justicia del Trabajo. De este modo, ante la incertidumbre sobre el comportamiento de dirigentes y bases en la reapertura inminente de las negociaciones colectivas, para el peronismo urgía la sanción de esta norma.

\section{Reflexiones finales}

Durante el primer peronismo se modificaron las formas de intervención estatal en los conflictos colectivos, en el marco de una serie de transformaciones mayores que implicaron un fortalecimiento del poder del PEN en la regulación de la relación capital-trabajo, viabilizada a través de un área especializada y acrecentada, como fue Trabajo y Previsión.

Allí se crearon nuevas dependencias con poderes sancionadores y se formularon protocolos de acción frente a los conflictos colectivos que se pusieron a prueba durante la gestión y cuyos avatares ameritarían un análisis más profundo mediante la reconstrucción del accionar del personal en conflictos concretos. La modalidad de procurar mejoras sociales mediante la negociación entre partes supervisada por el Estado tenía la ventaja de ser flexible y moverse en función de la correlación de fuerzas de cada rama económica. En el seno de reparticiones como la Dirección de Trabajo y Acción Social Directa se capitalizaron experiencias que permitieron licuar focos de recelo político ante el gobierno y que repercutieron en debates especializados y en la forma legal que adquiriría la convención colectiva en 1953.

Cuestiones relacionadas con el contexto político y económico, condujeron a la elevación del proyecto de ley en un período en que, tras la Reforma Constitucional y la crisis económica, el peronismo se encontraba reacomodando las expectativas de las organizaciones sindicales y presionaba a los empresarios para que se organizaran. La promulgación de la ley reafirmaba el rol del MTyP como autoridad de aplicación a la vez que cerraba la posibilidad de cuestionar la acción del Ejecutivo mediante el recurso al Poder Judicial, pulseada institucional que se remontaba al nacimiento mismo de la STyP. En el cruce entre la negociación y los intereses políticos, las luchas sociales y las cuestiones técnicas e institucionales, el Estado daba un paso más en su fortalecimiento institucional.

\section{Referencias}

Ajmechet, S. (s/a). La conformación de la Cámara de Diputados a partir de las elecciones legislativas de 1951.2 Recuperado de: http://www.unsam.edu.ar/escuelas/politica/centro historia politica/materiales/Confor maci\%C3\%B3n\%20de\%20la\%20C\%C3\%A1mara\%20de\%20Diputados\%2019461955/Conformaci\%C3\%B3n\%20C\%C3\%A1mara\%20de\%20Diputados\%20\%20Elecciones\%201951.pdf 
Amillano, A. (1939). Legislación Nacional del Trabajo: recopilación de leyes, decretos, resoluciones ministeriales, resoluciones del Departamento nacional del trabajo y otras disposiciones, tratados y convenios internacionales. Buenos Aires: Junta Central de la Acción Católica Argentina.

Belini, C. (2009). La industria peronista, La industria peronista: 1946-1955, políticas públicas y cambio estructural. Buenos Aires: Edhasa. Recuperado de: http://books.google.co.cr/books/about/La industria peronista.html?id=1psgQwAACA AJ\&redir esc $=y$

Bertolo, M. (julio-diciembre, 2011). Los primeros pasos de la negociación colectiva en la Argentina. Cuadernos del CIESAL, (10), 71-95. Recuperado de: http://www.fcpolit.unr.edu.ar/wp-content/uploads/art Bertolo.pdf

Berrotarán, P. (2003). Del plan a la planificación: El Estado durante la época peronista. Buenos Aires: Imago Mundi. Recuperado de: http://www.peronlibros.com.ar/content/berrotaran-patricia-del-plan-laplanificaci\%C3\%B3n-el-estado-durante-la-\%C3\%A9poca-peronista

Biernat, C. (2007). ¿Buenos o útiles? La política inmigratoria del peronismo. Buenos Aires: Biblos. Recuperado de: http://www.editorialbiblos.com.ar/ficha-de-libro/?bid=11535

Campione, D. (2007). Orígenes estatales del peronismo. Buenos Aires: Miño y Dávila. Recuperado de: http://www.minoydavila.com/origenes-estatales-del-peronismo.html

Cuando el primer obrero le dio la mano a Perón. (diciembre, 1953). Mundo Peronista, III, (56), $\quad$ p. 31. Recuperado de: http://www.ruinasdigitales.com/revistas/mundoperonista/Mundo\%20Peronista\%2056. pdf

Cultivo patronal de la huelga. (23 de setiembre de 1938). CGT, (231), p. 1.

Del Campo, H. (2006). Sindicalismo y peronismo. Los comienzos de un vínculo perdurable. Buenos Aires: Siglo XXI. Recuperado de: http://www.sigloxxieditores.com.ar/fichaLibro.php?libro=978-987-629-250-4

Derecho del Trabajo. (1944). Tomo IV, pp. 412-413 y 457-460. Argentina.

Deveali, M. (1952). Curso de Derecho Sindical y de la Previsión Social. Buenos Aires: Víctor P. de Zavalía S.A.

Diario de Sesiones de la Cámara de Diputados de la Nación Argentina. (1953). Reunión 38으, 1750-1817. Argentina.

Doyon, L. (2006). Perón y los trabajadores. Los orígenes del sindicalismo peronista. 19431955. Buenos Aires: Siglo XXI. Recuperado de: http://books.google.co.cr/books/about/Per\%C3\%B3n y los trabajadores.html?id=QX xFAAAAYAAJ\&redir esc $=y$

Freigeiro, E. (1941). El adelanto de nuestro comercio e industria hace indispensable la creación del Ministerio del Trabajo. Boletín del Trabajo de la República Argentina, (XVII), 19. 
Gaudio, R. y Pilone, J. (julio-setiembre, 1983). El desarrollo de la negociación colectiva durante la etapa de modernización industrial en la Argentina. 1935-1943. Desarrollo Económico, 23(90), 255-286. Recuperado de: http://de.ides.org.ar/desarrolloeconomico-no-90/

Gaudio, R. y Pilone, J. (julio-setiembre, 1984). Estado y relaciones laborales en el período previo al surgimiento del peronismo, 1935-1943. Desarrollo Económico, 24(94), 235273. Recuperado de: http://de.ides.org.ar/desarrollo-economico-no-94/

Hroncic, H. F. (1924). El Ministerio del Trabajo: necesidad y conveniencia de su creación. Jurisprudencia Argentina, Tomo 13, pp.67-68.

La 'legalidad' de las huelgas no puede estar supeditada a la voluntad de un hombre. (enero, 1949). El Trabajador de la Carne, II, (13), p. 5. Argentina.

Levaggi, A. (2006). Historia del Derecho Argentino del Trabajo (1800-2000). Revista lushistoria. Recuperado

de: http://www.ijeditores.com.ar/articulos.php?idarticulo=61997\&print=2

Lobato, M. (2004). La vida en las fábricas Trabajo, protesta y política en una comunidad obrera. Berisso (1904-1970). Buenos Aires: Editorial Prometeo.

Lobato, M. (enero-noviembre, 2007). Historia de las instituciones laborales en Argentina: una asignatura pendiente, Revista de Trabajo, 3(4), 145-154. Recuperado de: http://www.trabajo.gov.ar/left/estadisticas/descargas/revistaDeTrabajo/2007n04 revis taDeTrabajo/2007n04 a09 mzLobato.pdf

Luciani, M. (2014), El primer peronismo y la jerarquización de las agencias estatales del trabajo 1943-1955 (Tesis de maestría inédita). Instituto de Altos Estudios Sociales /Universidad Nacional de San Martín, Buenos Aires, Argentina.

Luna, F. (1975). El 45. Buenos Aires: Editorial Sudamericana.

Males reparables en el D. N. del Trabajo. (24 de febrero de 1939). CGT, (253). Argentina.

Memoria Ministerial Estatal de Argentina de la STyP. (1947). Argentina.

Memoria Ministerial Estatal de Argentina Junio 1946 a Diciembre 1951, MTyP. (1951). Argentina.

Memoria Ministerial Estatal de Argentina del MTyP. (1951). Argentina.

Monzalvo, L (1975). Testigo de la primera hora del peronismo. Buenos Aires: Pleamar. http://books.google.co.cr/books/about/Testigo de la primera hora del Peronismo.h tml?id=rkjiAAAAMAAJ\&redir esc $=y$

Nuestra Federación apoya y estimula a los funcionarios correctos (enero 1948). El Trabajador de la Carne, I, (1), p. 5.

Oszlak, O. (1980). Políticas públicas y regímenes políticos: reflexiones a partir de algunas experiencias latinoamericanas. Estudios CEDES, 3(2), 1-38. Recuperado de: http://unpan1.un.org/intradoc/groups/public/documents/un-dpadm/unpan040090.pdf 
Palacio, J. M. (2013). El peronismo y la invención de la justicia del trabajo en la Argentina, Nuevo Mundo Mundos Nuevos. Recuperado de: http://nuevomundo.revues.org/65765

Plan de Gobierno 1947-1951. (1947-1951). Trabajo y Previsión. Exposición analítica, STyP. Argentina.

Por el fiel cumplimiento de la legislación del trabajo en las dependencias del Estado, provincias y municipios. (9 y 16 de octubre de 1942). CGT, (439), p. 6 y (440), p. 6. Argentina.

Ramacciotti, K. (2009). La política sanitaria del peronismo. Buenos Aires: Biblos. Recuperado de: http://www.editorialbiblos.com.ar/ficha-de-libro/?bid=11698

Rein, R. (2006). Juan Atilio Bramuglia. Bajo la sombra del líder. La segunda línea de liderazgo peronista. Buenos Aires: Lumiere. Recuperado de: http://www.edicioneslumiere.com/obra.php?idioma=1\&tipo=2\&id=100

Schjolden, L. (2002). Suing for justice: labor and the courts in Argentina, 1900-1943 (Tesis de doctorado inédita). Universidad de California, Berkeley, Estados Unidos: http://phdtree.org/pdf/25371563-suing-for-justice-labor-and-the-courts-in-argentina1900-1943/

Segundo Plan Quinquenal - capítulo II. (1953). Revista de Trabajo y Previsión, (1), 40-44.

Soprano, G (2000). El Departamento Nacional del Trabajo y su proyecto de regulación estatal de las relaciones capital-trabajo en Argentina. 1907-1943. En J. Panettieri (Ed.), Argentina: trabajadores entre dos guerras (pp. 31-53). Buenos Aires: Eudeba.

Soprano, G (2009). 'Haciendo inspección'. Un análisis del diseño y aplicación de la inspección laboral por los funcionarios del Departamento Nacional del Trabajo (19071914). En E. Bohoslavsky y G. Soprano (Eds.), Un estado con rostro humano. Funcionarios e instituciones estatales en la Argentina, de 1880 a la actualidad (pp. 85-120). Buenos Aires: Prometeo. Recuperado de: http://www.prometeoeditorial.com/catalogo/detalle.php?id libro=521

Stagnaro, A. (2012). Los Tribunales del Trabajo como escenario del conflicto entre el capital y el trabajo. 1948-1960. (Tesis doctoral inédita). Universidad Nacional de La Plata, Buenos Aires, Argentina. Recuperado de: http://www.memoria.fahce.unlp.edu.ar/library?a=d\&c=tesis\&d=Jte802

Torre, J. (1990). La vieja guardia sindical y Perón. Sobre los orígenes del peronismo. Buenos Aires: Sudamericana. Recuperado de: http://books.google.co.cr/books/about/La Vieja Guardia Sindical y Per\%C3\%B3n.h tml?id=fwZIAAAAMAAJ\&redir esc $=y$

Una repartición que retrocede. (3 de marzo de 1939), CGT, (254), p. 1. Argentina.

Unsaín, A. (1945). Síntesis del régimen legal de las asociaciones profesionales. Derecho del Trabajo, Tomo V, pp. 529-538. Argentina 
Zanatta, L. (2011). Eva Perón, una biografía política. Buenos Aires: Sudamericana. Recuperado de: http://books.google.co.cr/books?id=EJ4kRYzE3gsC\&pg=PT357\&lpg=PT357\&dq=Eva +Per\%C3\%B3n,+una+biograf\%C3\%ADa+pol\%C3\%ADtica.+Buenos+Aires:+Sudame ricana.\&source=bl\&ots=fSC6D0BkIP\&sig=WPXA6NrockwT3q9v5myVC65Ae1Q\&hl=e s\&sa=X\&ei=qBY8VOe7HJDLgwTiz|JI\&redir esc=y\#v=onepage\&q=Eva\%20Per\%C3 \%B3n\%2C\%20una\%20biograf\%C3\%ADa\%20pol\%C3\%ADtica.\%20Buenos\%20Aires $\% 3 \mathrm{~A} \% 20$ Sudamericana.\&f=false 